\title{
Transmission of SARS-CoV-2 on mink farms between humans and mink and back to humans
}

\author{
Bas B. Oude Munnink ${ }^{1 *}$, Reina S. Sikkema ${ }^{1}$, David F. Nieuwenhuijse ${ }^{1}$, Robert Jan Molenaar ${ }^{2}$, Emmanuelle \\ Munger ${ }^{1}$, Richard Molenkamp ${ }^{1}$, Arco van der Spek ${ }^{3}$, Paulien Tolsma ${ }^{4}$, Ariene Rietveld ${ }^{5}$, Miranda Brouwer ${ }^{5}$, \\ Noortje Bouwmeester-Vincken ${ }^{6}$, Frank Harders ${ }^{7}$, Renate Hakze-van der Honing ${ }^{7}$, Marjolein C. A. Wegdam- \\ Blans $^{8}$, Ruth J. Bouwstra ${ }^{2}$, Corine GeurtsvanKessel', Annemiek A. van der Eijki ${ }^{1}$, Francisca C. Velkers ${ }^{9}$, Lidwien \\ A. M. Smit ${ }^{10}$, Arjan Stegeman' ${ }^{9}$, Wim H. M. van der Poel ${ }^{7}$, Marion P. G. Koopmans ${ }^{1}$ \begin{abstract}
Deventer, Netherlands. ${ }^{3}$ Netherlands Food and Consumer Product Safety Authority (NVWA), Utrecht, Netherlands. ${ }^{4}$ Municipal health Services GGD Brabant-Zuidoost, Eindhoven, Netherlands. ${ }^{5}$ Municipal health Services GGD Hart voor Brabant, 's-Hertogenbosch, Netherlands. ${ }^{6}$ Municipal health Services GGD Limburg-Noord, Venlo, Netherlands. ${ }^{7}$ Wageningen Bioveterinary Research, Lelystad, Netherlands. ${ }^{8}$ Stichting PAMM, Veldhoven, Netherlands. ${ }^{9}$ Farm Animal Health, Utrecht University, Utrecht, Netherlands. ${ }^{10}$ Institute for Risk Assessment Sciences (IRAS), Utrecht University, Utrecht, Netherlands.

*Corresponding author: Email: b.oudemunnink@erasmusmc.nl
\end{abstract} \\ ${ }^{1}$ Erasmus MC, Department of Viroscience, WHO collaborating centre for arbovirus and viral hemorrhagic fever Reference and Research, Rotterdam, Netherlands. ${ }^{2}$ Royal GD,
}

Animal experiments have shown that non-human primates, cats, ferrets, hamsters, rabbits and bats can be infected by SARS-CoV-2. In addition, SARS-CoV-2 RNA has been detected in felids, mink and dogs in the field. Here, we describe an in-depth investigation using whole genome sequencing of outbreaks on 16 mink farms and the humans living or working on these farms. We conclude that the virus was initially introduced from humans and has since evolved, most likely reflecting widespread circulation among mink in the beginning of the infection period several weeks prior to detection. Despite enhanced biosecurity, early warning surveillance and immediate culling of infected farms, transmission occurred between mink farms in three big transmission clusters with unknown modes of transmission. Sixty-eight percent (68\%) of the tested mink farm residents, employees and/or contacts had evidence of SARS-CoV-2 infection. Where whole genomes were available, these persons were infected with strains with an animal sequence signature, providing evidence of animal to human transmission of SARS-CoV-2 within mink farms.

Late December 2019, SARS-CoV-2 was identified as causing in a viral pneumonia outbreak, possibly related to a seafood and a live animal market in Wuhan, China (1). Since then, SARS-CoV-2 spread across the world and by October 82020 , over $36,100,000$ people had been infected with SARS-CoV-2 resulting in over $1,000,000$ deaths (2). In the Netherlands, over 155,000 infections have been confirmed, over 6,500 SARS-CoV-2 related deaths have been reported, and nonpharmaceutical interventions have been put into place to prevent further spread of SARS-CoV-2 (3).

In view of the similarities of the new virus with SARSCoV-1, a zoonotic origin of the outbreak was suspected linked to the Wuhan fresh market where various animals were sold including fish, shellfish, poultry, wild birds and exotic animals. The finding of cases with onset of illness well before the period observed in the Wuhan market-associated cluster suggests the possibility of other sources (4). Although closely related coronaviruses found in bats $(5,6)$ and pangolins $(7,8)$ have greatest sequence identity to SARS-CoV-2, the most likely divergence of SARS-CoV-2 from the most closely related bat sequence is estimated somewhere between 1948-1982 (9). Therefore, the animal reservoir(s) of SARS-CoV-2 is (are) yet to be identified.
Similar to SARS-CoV-1, SARS-CoV-2 binds to the host angiotensin-converting enzyme 2 (ACE2) receptor. Based on ACE2 similarities, a range of different animals have been used as models. Experimental infections in dogs (10), cats (10-13), ferrets $(10,14)$, hamsters $(15,16)$, rhesus macaques (17), tree shrew (18), cynomolgus macaques (19), African green monkey (20), common marmosets (21), rabbits (22), and fruit bats (23) have shown that these species are susceptible to SARS-CoV-2, and experimentally infected cats, tree shrews, hamsters and ferrets could also transmit the virus. In contrast, experimental infection of pigs and several poultry species with SARS-CoV-2 proved to be unsuccessful (10, 23, 24). SARS-CoV-2 has also sporadically been identified in naturally infected animals. In the USA and in Hong Kong, SARSCoV-2 RNA has been detected in dogs (25). In the Netherlands, France, Hong Kong, Belgium, Spain and the USA, cats have tested positive by RT-PCR for SARS-CoV-2 (26-30). Furthermore, SARS-CoV-2 has been detected in four tigers and three lions in a zoo in New York (31). In Italy, the Netherlands and in Wuhan, antibodies to SARS-CoV-2 have been detected in cats $(29,32,33)$. Recently, SARS-CoV-2 was detected in farmed mink (Neovison vison) resulting in signs of respiratory disease and increased mortality $(29,34)$. 
In response to the outbreaks in mink farms, the Dutch national response system for zoonotic diseases was activated, and it was concluded that the public health risk of exposure to animals with SARS-CoV-2 was low, but that there was a need for increased awareness of possible involvement of animals in the COVID-19 epidemic. Therefore, from May 20th 2020 onwards, mink farmers, veterinarians and laboratories were obliged to report symptoms in mink (family Mustelidae) to the Netherlands Food and Consumer Product Safety Authority (NFCPSA) and an extensive surveillance system was set up (35).

Whole genome sequencing (WGS) can be used to monitor the emergence and spread of pathogens (36-39). As part of the surveillance effort in the Netherlands over 1,750 SARSCoV-2 viruses have been sequenced to date from patients from different parts of the Netherlands (40). Here, we describe an in-depth investigation into the SARS-CoV-2 outbreak in mink farms and mink farm employees in the Netherlands, combining epidemiological information, surveillance data and WGS on the human-animal interface.

SARS-CoV-2 was first diagnosed on two mink farms in the Netherlands on April 23rd (NB1) and April 25th (NB2), respectively. After the initial detection of SARS-CoV-2 on these farms an in-depth investigation was initiated to identify potential transmission routes and to perform an environmental and occupational risk assessment. Here, we describe the results of the outbreak investigation of the first 16 SARS-CoV-2 infected mink farms by combining SARS-CoV-2 diagnostics, WGS and in-depth interviews.

Owners and employees of the 16 SARS-CoV-2 positive mink farms were included in the contact tracing investigation of the municipal health services and tested according to national protocol. In total, 97 individuals were tested by either serological assays and/or RT-PCR. In total, 43 out of 88 (49\%) upper-respiratory tract samples tested positive by RTPCR while 38 out of 75 (51\%) serum samples tested positive for SARS-CoV-2 specific antibodies. In total, 66 of 97 (68\%) of the persons tested had evidence for SARS-CoV-2 infection (Table 1).

During the interview on April 28th, four of five employees from NB1 reported that they had experienced respiratory symptoms before the outbreak was detected in minks, but none of them had been tested for SARS-CoV-2. The first dates of their symptoms ranged from April 1st to May 9th. For 16 of the mink, sampled on April 28th, and one farm employee, sampled on May 4th, a WGS was obtained (hCov-19/Netherlands/NoordBrabant_177/2020). The human sequence clusters within the mink sequences although it displayed 7 nucleotides difference with the closest mink sequence (Fig. 1 and cluster A in Figs. 2 and 3). On farm NB2, SARS-CoV-2 was diagnosed on April 25th. Retrospective analysis showed that one employee from NB2 had been hospitalized with
SARS-CoV-2 on March 31st. All samples from the eight employees taken on April 30th were negative by RT-PCR but tested positive for SARS-CoV-2 antibodies. The virus sequence obtained from animals was distinct from that of farm NB1, indicating a separate introduction (Figs. 2 and 3, cluster B).

On mink farm NB3 SARS-CoV-2 infection was diagnosed on May 7th. Initially all seven employees tested negative for SARS-CoV-2, but when retested between May 19th and May 26th after developing COVID-19 related symptoms, five of seven individuals working or living on the farm tested positive for SARS-CoV-2 RNA. WGS were obtained from these five individuals and the clustering of these sequences with the sequences derived from mink from NB3, together with initial negative test result and the start of the symptoms, indicate that the employees were infected with SARS-CoV-2 after mink on the farm became infected. An additional infection was identified from contact-tracing: a close contact of one of the employees who did not visit the farm, became infected with the SARS-CoV-2 strain found in farm NB3. Animal and human sequences from farm NB3 were close to those from farm NB1, and both fell in cluster A.

Similarly, on mink farm NB7 zoonotic transmission from mink to human likely occurred. On this farm, SARS-CoV-2 infection in mink was diagnosed on May 31st and employees initially tested negative for SARS-CoV-2 however, subsequently several NB7 employees began to show symptoms. Samples were taken between June 10th and July 1st from 10 employees of which eight tested positive for SARS-CoV-2 RNA. From two NB7 employee samples, WGS showed their virus sequences clustered with the sequences from the mink at this farm.

The sequences generated from mink farms and from mink farm employees were compared with the national database consisting of around 1,775 WGS. To discriminate between community acquired infections and mink farm related SARSCoV-2 infection, and to determine the potential risk for people living close to mink farms, WGS was also performed on 34. SARS-CoV-2 positive samples, sampled from 04-03-2020 until 29-04-2020, from individuals who live in the same fourdigit postal code area as the first four mink farms. These local sequences, sampled in a proxy of around $19 \mathrm{~km}^{2}$, reflected the general diversity of SARS-CoV-2 seen in the Netherlands and were not related to the clusters of mink sequences found on the mink farms, thereby indicating no spill-over to people living in close proximity to mink farms had occurred and that the sequences from SARS-CoV-2 infected animals and farm workers clustered by farm (sequences from community shown in magenta, Fig. 2). The sequences from the mink farm investigation were also compared to sequences from Poland ( $\mathrm{n}$ $=65$ ), since many of the mink farm workers were seasonal migrants from Poland, but these sequences were more divergent. 
Phylogenetic analysis of the mink SARS-CoV-2 genomes showed that mink sequences of 16 farms grouped into 5 different clusters (Figs. 2 and 3). Viruses from farms NB1, NB3, NB4, NB8, NB12, NB13 and NB16 belonged to cluster A, sequences from NB2 formed a distinct cluster (B), those from farms NB6, NB7, NB9 and NB14 formed cluster C, NB5, NB8, NB10 and NB15 formed cluster D, and NB11 had sequences designated as cluster E. On farm NB8, SARS-CoV-2 viruses were found from cluster A and cluster D. A detailed inventory of possible common characteristics, including farm owner, shared personnel, feed supplier and veterinary service provider, was made. Multiple farms within a cluster shared the same owner; however, in most cases no common factor could be identified for most farms and clustering could not be explained by geographic distance (Table 2 and Fig. 4).

In total 18 sequences from mink farm employees or close contacts were generated from seven different farms. In most cases, these human sequences were near-identical to the mink sequences from the same farm. For NB1 the situation was different and the human sequence clusters deeply within the sequences derived from mink (Fig. 1), with seven nucleotides difference from the closest related mink sequence. This was also the case on farm NB14, with four nucleotides difference from the closest related mink sequence. Employees sampled at mink farm NB8 clustered with animals from NB12, likely because personnel were exchanged between these two farms.

SARS-CoV-2 was detected on mink farm NB1-NB4 after reports of respiratory symptoms and increased mortality in mink. The sequences from farm NB1 showed between 0 and 9 single nucleotide polymorphisms (SNPs) difference (average 3.9 nucleotides) and sequences from NB2 had between 0 and 8 SNPs difference (average of 3.6), which is more than generally observed in outbreaks in human settings. In addition, two deletions, one of 12 and one of 134 nucleotides were observed in single sequence from NB1. The sequences of mink at NB6 had between 0 and 12 SNPs differences and in one sequence a deletion of 9 nucleotides was observed, whereas diversity was lower for the subsequent farm sequences (Table 2). After the initial detection of SARS-CoV-2, farms were screened weekly. The first, second, fifth and sixth weekly screening yielded new positives.

Several non-synonymous mutations were identified among the mink sequences compared to the Wuhan reference sequence NC_045512.2. However, no particular amino acid substitutions were found in all mink samples (fig. S1). Of note, three of the clusters had the position $614 \mathrm{G}$ variant (clusters $\mathrm{A}, \mathrm{C}$ and $\mathrm{E}$ ), and two had the original variant. There were no obvious differences in the presentation of disease in animals or humans between clusters based on the data available at this stage, but further data collection and analysis also for cases after NB16, are ongoing to investigate this further. The mutations we observed can also be found in the general human population and the same mutations also were found in human cases which were related to the mink farms.

Here we show ongoing SARS-CoV-2 transmission in mink farms and spill-over events to humans. More research in minks and other mustelid species is important to understand if these species are at risk of becoming a reservoir of SARSCoV-2. After the detection of SARS-CoV-2 on mink farms, $68 \%$ of the tested farm workers and/or relatives or contacts were to be or have been infected with SARS-CoV-2, indicating that contact with SARS-CoV-2 infected mink is a risk factor for contracting COVID-19. Recently, a 8-fold increase in cytidineto-uridine $(\mathrm{C}->\mathrm{U})$ compared to $\mathrm{U}->\mathrm{C}$ substitutions were described, suggestive of host adaptation (41). In the mink sequences we observed a 3.5-fold increase in $\mathrm{C}->\mathrm{U}$ compared to $\mathrm{U}->\mathrm{C}$ substitutions but the number of substitutions was limited (185).

A high diversity in the sequences from some mink farms was observed which is likely explained by multiple generations of viral infections in animals before the increase in mortality was detected. The current estimates are that the substitution rate of SARS-CoV-2 is around $1.16^{*} 10^{\wedge}-3$ substitutions/site/year in the human population (42), which corresponds to around one mutation per two weeks. This could mean that the virus was already circulating in mink farms for some time. However, there was also a relatively high sequence diversity observed in farms which still tested negative one week prior, hinting toward a faster evolutionary rate of the virus in the mink population. Mink farms have large populations of animals, living at high density, which could promote virus transmission. However, the moment of introduction was not known, making it difficult to draw definite conclusions on the substitution rate in mink farms. Our sequencing did not reveal any systematic mutations that would need to be assessed for potential phenotypic effects. Generation intervals for SARS-CoV-2 in humans have been estimated to be around 4-5 days (43), but with high dose exposure in a farm with a high number and density of animals, this could potentially be shorter.

Further evidence that animals were the most likely source of human infection was provided by the clear phylogenetic separation between mink farm related human and animal sequences and sequences from human cases within the same 4digit postal code area. However, some of the farm related humans may have been infected within their household, and not directly from mink. Spill-back into the community living in the same 4-digit postal code area was not observed in our sequence data.

So far, the investigation failed to identify common factors that might explain farm-to-farm spread: possibly via temporary workers who were not included in testing. Since our observations, SARS-CoV-2 infections have also been described 
in mink farms elsewhere (44-46). It is imperative that fur production and trading sector should not become a reservoir for future spillover of SARS-CoV-2 to humans.

\section{REFERENCES AND NOTES}

1. N. Zhu, D. Zhang, W. Wang, X. Li, B. Yang, J. Song, X. Zhao, B. Huang, W. Shi, R. Lu, P. Niu, F. Zhan, X. Ma, D. Wang, W. Xu, G. Wu, G. F. Gao, W. Tan; China Novel Coronavirus Investigating and Research Team, A novel coronavirus from patients with pneumonia in China, 2019. N. Engl. J. Med. 382, 727-733 (2020). doi:10.1056/NEJMoa2001017 Medline

2. E. Dong, H. Du, L. Gardner, An interactive web-based dashboard to track COVID-19 in real time. Lancet Infect. Dis. 20, 533-534 (2020). doi:10.1016/S14733099(20)30120-1 Medline

3. B. B. Oude Munnink, D. F. Nieuwenhuijse, M. Stein, Á. O'Toole, M. Haverkate, M. Mollers, S. K. Kamga, C. Schapendonk, M. Pronk, P. Lexmond, A. van der Linden, T. Bestebroer, I. Chestakova, R. J. Overmars, S. van Nieuwkoop, R. Molenkamp, A. A. van der Eijk, C. GeurtsvanKessel, H. Vennema, A. Meijer, A. Rambaut, J. van Dissel, R. S. Sikkema, A. Timen, M. Koopmans; Dutch-Covid-19 response team, Rapid SARS-CoV-2 whole-genome sequencing and analysis for informed public health decision-making in the Netherlands. Nat. Med. 26, 1405-1410 (2020). doi:10.1038/s41591-020-0997-y Medline

4. F. Wu, S. Zhao, B. Yu, Y. M. Chen, W. Wang, Z. G. Song, Y. Hu, Z. W. Tao, J. H. Tian, Y. Y. Pei, M. L. Yuan, Y. L. Zhang, F. H. Dai, Y. Liu, Q. M. Wang, J. J. Zheng, L. Xu, E. C. Holmes, Y. Z. Zhang, A new coronavirus associated with human respiratory disease in China. Nature 579, 265-269 (2020). doi:10.1038/s41586-020-2008-3 Medline

5. H. Zhou, X. Chen, T. Hu, J. Li, H. Song, Y. Liu, P. Wang, D. Liu, J. Yang, E. C. Holmes, A. C. Hughes, Y. Bi, W. Shi, A Novel Bat Coronavirus Closely Related to SARS-CoV2 Contains Natural Insertions at the S1/S2 Cleavage Site of the Spike Protein. Curr. Biol. 30, 3896 (2020). doi:10.1016/i.cub.2020.05.023 Medline

6. P. Zhou, X. L. Yang, X. G. Wang, B. Hu, L. Zhang, W. Zhang, H. R. Si, Y. Zhu, B. Li, C. L. Huang, H. D. Chen, J. Chen, Y. Luo, H. Guo, R. D. Jiang, M. Q. Liu, Y. Chen, X. R. Shen, X. Wang, X. S. Zheng, K. Zhao, Q. J. Chen, F. Deng, L. L. Liu, B. Yan, F. X. Zhan, Y. Y. Wang, G. F. Xiao, Z. L. Shi, A pneumonia outbreak associated with a new coronavirus of probable bat origin. Nature 579, 270-273 (2020). doi:10.1038/s41586-020-2012-7 Medline

7. T. T. Y. Lam, N. Jia, Y. W. Zhang, M. H. Shum, J. F. Jiang, H. C. Zhu, Y. G. Tong, Y. X. Shi, X. B. Ni, Y. S. Liao, W. J. Li, B. G. Jiang, W. Wei, T. T. Yuan, K. Zheng, X. M. Cui, J. Li, G. Q. Pei, X. Qiang, W. Y. Cheung, L. F. Li, F. F. Sun, S. Qin, J. C. Huang, G. M. Leung, E. C. Holmes, Y. L. Hu, Y. Guan, W. C. Cao, Identifying SARS-CoV-2-related coronaviruses in Malayan pangolins. Nature 583, 282-285 (2020). doi:10.1038/s41586-020-2169-0 Medline

8. G. Z. Han, Pangolins Harbor SARS-CoV-2-Related Coronaviruses. Trends Microbiol. 28, 515-517 (2020). doi:10.1016/j.tim.2020.04.001 Medline

9. M. F. Boni, P. Lemey, X. Jiang, T. T. Y. Lam, B. W. Perry, T. A. Castoe, A. Rambaut, D. L. Robertson, Evolutionary origins of the SARS-CoV-2 sarbecovirus lineage responsible for the COVID-19 pandemic. Nat. Microbiol. 5, 1408-1417 (2020). doi:10.1038/s41564-020-0771-4 Medline

10. J. Shi, Z. Wen, G. Zhong, H. Yang, C. Wang, B. Huang, R. Liu, X. He, L. Shuai, Z. Sun, Y. Zhao, P. Liu, L. Liang, P. Cui, J. Wang, X. Zhang, Y. Guan, W. Tan, G. Wu, H. Chen, Z. Bu, Susceptibility of ferrets, cats, dogs, and other domesticated animals to SARS-coronavirus 2. Science 368, 1016-1020 (2020). doi:10.1126/science.abb7015 Medline

11. P. J. Halfmann, M. Hatta, S. Chiba, T. Maemura, S. Fan, M. Takeda, N. Kinoshita, S.I. Hattori, Y. Sakai-Tagawa, K. Iwatsuki-Horimoto, M. Imai, Y. Kawaoka, Transmission of SARS-CoV-2 in Domestic Cats. N. Engl. J. Med. 383, 592-594 (2020). doi:10.1056/NEJMc2013400 Medine

12. COVID-19 confirmed in pet cat in the UK - GOV.UK, (available at www.gov.uk/government/news/covid-19-confirmed-in-pet-cat-in-the-uk).

13. I. Ruiz-Arrondo, A. Portillo, A. M. Palomar, S. Santibáñez, P. Santibáñez, C. Cervera, J. A. Oteo, Detection of SARS-CoV-2 in pets living with COVID-19 owners diagnosed during the COVID-19 lockdown in Spain: A case of an asymptomatic cat with SARS-CoV-2 in Europe. Transbound. Emerg. Dis. 10.1111/tbed.13803 (2020). doi:10.1111/tbed.13803 Medline
14. M. Richard, A. Kok, D. de Meulder, T. M. Bestebroer, M. M. Lamers, N. M. A. Okba, M. Fentener van Vlissingen, B. Rockx, B. L. Haagmans, M. P. G. Koopmans, R. A. M. Fouchier, S. Herfst, SARS-CoV-2 is transmitted via contact and via the air between ferrets. Nat. Commun. 11, 3496 (2020). doi:10.1038/s41467-02017367-2 Medline

15. S. F. Sia, L.-M. Yan, A. W. H. Chin, K. Fung, K. T. Choy, A. Y. L. Wong, P. Kaewpreedee, R. A. P. M. Perera, L. L. M. Poon, J. M. Nicholls, M. Peiris, H. L. Yen, Pathogenesis and transmission of SARS-CoV-2 in golden hamsters. Nature 583, 834-838 (2020). doi:10.1038/s41586-020-2342-5 Medline

16. J. F. W. Chan, A. J. Zhang, S. Yuan, V. K. M. Poon, C. C. S. Chan, A. C. Y. Lee, W. M. Chan, Z. Fan, H. W. Tsoi, L. Wen, R. Liang, J. Cao, Y. Chen, K. Tang, C. Luo, J. P. Cai, K. H. Kok, H. Chu, K. H. Chan, S. Sridhar, Z. Chen, H. Chen, K. K. W. To, K. Y. Yuen, Simulation of the clinical and pathological manifestations of Coronavirus Disease 2019 (COVID-19) in golden Syrian hamster model: Implications for disease pathogenesis and transmissibility. Clin. Infect. Dis. 10.1093/cid/ciaa325 (2020). doi:10.1093/cid/ciaa325 Medline

17. V. J. Munster, F. Feldmann, B. N. Williamson, N. van Doremalen, L. Pérez-Pérez, J. Schulz, K. Meade-White, A. Okumura, J. Callison, B. Brumbaugh, V. A. Avanzato, R. Rosenke, P. W. Hanley, G. Saturday, D. Scott, E. R. Fischer, E. de Wit, Respiratory disease in rhesus macaques inoculated with SARS-CoV-2. Nature 585, 268-272 (2020). doi:10.1038/s41586-020-2324-7 Medline

18. Y. Zhao, J. Wang, D. Kuang, J. Xu, M. Yang, C. Ma, S. Zhao, J. Li, H. Long, K. Ding, J. Gao, J. Liu, H. Wang, H. Li, Y. Yang, W. Yu, J. Yang, Y. Zheng, D. Wu, S. Lu, H. Liu, X. Peng, Susceptibility of tree shrew to SARS-CoV-2 infection. Sci. Rep. 10, 16007 (2020). doi:10.1038/s41598-020-72563-w Medline

19. B. Rockx, T. Kuiken, S. Herfst, T. Bestebroer, M. M. Lamers, B. B. Oude Munnink, D. de Meulder, G. van Amerongen, J. van den Brand, N. M. A. Okba, D. Schipper, P. van Run, L. Leijten, R. Sikkema, E. Verschoor, B. Verstrepen, W. Bogers, J. Langermans, C. Drosten, M. Fentener van Vlissingen, R. Fouchier, R. de Swart, M. Koopmans, B. L. Haagmans, Comparative pathogenesis of COVID-19, MERS, and SARS in a nonhuman primate model. Science 368, 1012-1015 (2020). doi:10.1126/science.abb7314 Medline

20. C. Woolsey, V. Borisevich, A. N. Prasad, K. N. Agans, D. J. Deer, N. S. Dobias, J. C. Heymann, S. L. Foster, C. B. Levine, L. Medina, K. Melody, J. B. Geisbert, K. A. Fenton, T. W. Geisbert, R. W. Cross, Establishment of an African green monkey model for COVID-19. bioRxiv (2020). https://doi.org/10.1101/2020.05.17.100289.

21. S. Lu, Y. Zhao, W. Yu, Y. Yang, J. Gao, J. Wang, D. Kuang, M. Yang, J. Yang, C. Ma, J. Xu, X. Qian, H. Li, S. Zhao, J. Li, H. Wang, H. Long, J. Zhou, F. Luo, K. Ding, D. Wu, Y. Zhang, Y. Dong, Y. Liu, Y. Zheng, X. Lin, L. Jiao, H. Zheng, Q. Dai, Q. Sun, Y. Hu, C. Ke, H. Liu, X. Peng, Comparison of nonhuman primates identified the suitable model for COVID-19. Signal Transduct. Target. Ther. 5, 157 (2020). doi:10.1038/s41392-020-00269-6 Medline

22. B. L. Haagmans, D. Noack, N. M. Okba, W. Li, C. Wang, R. de Vries, S. Herfst, D. de Meulder, P. van Run, B. Rijnders, C. Rokx, F. van Kuppeveld, F. Grosveld, C. GeurtsvanKessel, M. Koopmans, B. Jan Bosch, T. Kuiken, B. Rockx, SARS-CoV-2 neutralizing human antibodies protect against lower respiratory tract disease in a hamster model. bioRxiv (2020). https://doi.org/10.1101/2020.08.24.264630.

23. K. Schlottau, M. Rissmann, A. Graaf, J. Schön, J. Sehl, C. Wylezich, D. Höper, T. C. Mettenleiter, A. Balkema-Buschmann, T. Harder, C. Grund, D. Hoffmann, A. Breithaupt, M. Beer, Experimental Transmission Studies of SARS-CoV-2 in Fruit Bats, Ferrets, Pigs and Chickens. SSRN Electron. J. (2020). https://doi.org/10.2139/ssrn.3578792.

24. D. L. Suarez, M. J. Pantin-Jackwood, D. E. Swayne, S. A. Lee, S. M. Deblois, E. Spackman, Lack of susceptibility of poultry to SARS-CoV-2 and MERS-CoV. bioRxiv (2020). https://doi.org/10.1101/2020.06.16.154658.

25. T. H. C. Sit, C. J. Brackman, S. M. Ip, K. W. S. Tam, P. Y. T. Law, E. M. W. To, V. Y. T. Yu, L. D. Sims, D. N. C. Tsang, D. K. W. Chu, R. A. P. M. Perera, L. L. M. Poon, M. Peiris, Infection of dogs with SARS-CoV-2. Nature 586, 776-778 (2020). doi:10.1038/s41586-020-2334-5 Medline

26. C. Sailleau, M. Dumarest, J. Vanhomwegen, M. Delaplace, V. Caro, A. Kwasiborski, V. Hourdel, P. Chevaillier, A. Barbarino, L. Comtet, P. Pourquier, B. Klonjkowski, J. C. Manuguerra, S. Zientara, S. Le Poder, First detection and genome sequencing of SARS-CoV-2 in an infected cat in France. Transbound. Emerg. Dis. 10.1111/tbed.13659 (2020). doi:10.1111/tbed.13659 Medline 
27. A. Newman, D. Smith, R. R. Ghai, R. M. Wallace, M. K. Torchetti, C. Loiacono, L. S. Murrell, A. Carpenter, S. Moroff, J. A. Rooney, C. Barton Behravesh, First Reported Cases of SARS-CoV-2 Infection in Companion Animals - New York, March-April 2020. MMWR Morb. Mortal. Wkly. Rep. 69, 710-713 (2020). doi:10.15585/mmwr.mm6923e3 Medline

28. Promed Post - ProMED-mail, (available at https:/promedmailorg/promedpost/?id=7314521).

29. N. Oreshkova, R. J. Molenaar, S. Vreman, F. Harders, B. B. Oude Munnink, R. W Hakze-van der Honing, N. Gerhards, P. Tolsma, R. Bouwstra, R. S. Sikkema, M. G. Tacken, M. M. de Rooij, E. Weesendorp, M. Y. Engelsma, C. J. Bruschke, L. A. Smit, M. Koopmans, W. H. van der Poel, A. Stegeman, SARS-CoV-2 infection in farmed minks, the Netherlands, April and May 2020. Euro Surveill. 25, 2001005 (2020). doi:10.2807/1560-7917.ES.2020.25.23.2001005 Medline

30. J. Segalés, M. Puig, J. Rodon, C. Avila-Nieto, J. Carrillo, G. Cantero, M. T. Terrón, S. Cruz, M. Parera, M. Noguera-Julián, N. Izquierdo-Useros, V. Guallar, E. Vidal, A. Valencia, I. Blanco, J. Blanco, B. Clotet, J. Vergara-Alert, Detection of SARS-CoV2 in a cat owned by a COVID-19-affected patient in Spain. Proc. Natl. Acad. Sci. U.S.A. 117, 24790-24793 (2020). doi:10.1073/pnas.2010817117 Medline

31. R. Gollakner, I. Capua, Is COVID-19 the first pandemic that evolves into a panzootic? Vet. Ital. 56, 7-8 (2020). doi:10.12834/Vet|t.2246.12523.1 Medline

32. Q. Zhang, H. Zhang, K. Huang, Y. Yang, X. Hui, J. Gao, X. He, C. Li, W. Gong, Y. Zhang, C. Peng, X. Gao, H. Chen, Z. Zou, Z. Shi, M. Jin, SARS-CoV-2 neutralizing serum antibodies in cats: A serological investigation. bioRxiv (2020). https://doi.org/10.1101/2020.04.01.021196.

33. E. I. Patterson, G. Elia, A. Grassi, A. Giordano, C. Desario, M. Medardo, S. L. Smith, E. R. Anderson, T. Prince, G. T. Patterson, E. Lorusso, M. S. Lucente, G. Lanave, S. Lauzi, U. Bonfanti, A. Stranieri, V. Martella, F. S. Basano, V. R. Barrs, A. D. Radford, U. Agrimi, G. L. Hughes, S. Paltrinieri, N. Decaro, Evidence of exposure to SARSCoV-2 in cats and dogs from households in Italy. bioRxiv (2020). https://doi.org/10.1101/2020.07.21.214346.

34. R. J. Molenaar, S. Vreman, R. W. Hakze-van der Honing, R. Zwart, J. de Rond, E. Weesendorp, L. A. M. Smit, M. Koopmans, R. Bouwstra, A. Stegeman, W. H. M. van der Poel, Clinical and Pathological Findings in SARS-CoV-2 Disease Outbreaks in Farmed Mink (Neovison vison). Vet. Pathol. 57, 653-657 (2020). doi:10.1177/0300985820943535 Medline

35. Bedrijfsmatig gehouden dieren en SARS-CoV-2 | Nieuws en media | NVWA, (available at www.nvwa.nl/nieuws-en-media/actueleonderwerpen/corona/g/bedriifsmatig-gehouden-dieren-en-corona).

36. B. B. Oude Munnink, E. Münger, D. F. Nieuwenhuijse, R. Kohl, A. van der Linden, C. M. E. Schapendonk, H. van der Jeugd, M. Kik, J. M. Rijks, C. B. E. M. Reusken, M. Koopmans, Genomic monitoring to understand the emergence and spread of Usutu virus in the Netherlands, 2016-2018. Sci. Rep. 10, 2798 (2020). doi:10.1038/s41598-020-59692-y Medline

37. A. Arias, S. J. Watson, D. Asogun, E. A. Tobin, J. Lu, M. V. T. Phan, U. Jah, R. E. G. Wadoum, L. Meredith, L. Thorne, S. Caddy, A. Tarawalie, P. Langat, G. Dudas, N. R. Faria, S. Dellicour, A. Kamara, B. Kargbo, B. O. Kamara, S. Gevao, D. Cooper, M. Newport, P. Horby, J. Dunning, F. Sahr, T. Brooks, A. J. H. Simpson, E. Groppelli, G. Liu, N. Mulakken, K. Rhodes, J. Akpablie, Z. Yoti, M. Lamunu, E. Vitto, P. Otim, C. Owilli, I. Boateng, L. Okoror, E. Omomoh, J. Oyakhilome, R. Omiunu, I. Yemisis, D. Adomeh, S. Ehikhiametalor, P. Akhilomen, C. Aire, A. Kurth, N. Cook, J. Baumann, M. Gabriel, R. Wölfel, A. Di Caro, M. W. Carroll, S. Günther, J. Redd, D. Naidoo, O. G. Pybus, A. Rambaut, P. Kellam, I. Goodfellow, M. Cotten, Rapid outbreak sequencing of Ebola virus in Sierra Leone identifies transmission chains linked to sporadic cases. Virus Evol. 2, vew016 (2016). doi:10.1093/ve/vew016 Medline

38. N. R. Faria, M. U. G. Kraemer, S. C. Hill, J. Goes de Jesus, R. S. Aguiar, F. C. M. Iani, J. Xavier, J. Quick, L. du Plessis, S. Dellicour, J. Thézé, R. D. O. Carvalho, G. Baele, C.-H. Wu, P. P. Silveira, M. B. Arruda, M. A. Pereira, G. C. Pereira, J. Lourenço, U. Obolski, L. Abade, T. I. Vasylyeva, M. Giovanetti, D. Yi, D. J. Weiss, G. R. W. Wint, F. M. Shearer, S. Funk, B. Nikolay, V. Fonseca, T. E. R. Adelino, M. A. A. Oliveira, M. V. F. Silva, L. Sacchetto, P. O. Figueiredo, I. M. Rezende, E. M. Mello, R. F. C. Said, D. A. Santos, M. L. Ferraz, M. G. Brito, L. F. Santana, M. T. Menezes, R. M. Brindeiro, A. Tanuri, F. C. P. Dos Santos, M. S. Cunha, J. S. Nogueira, I. M. Rocco, A. C. da Costa, S. C. V. Komninakis, V. Azevedo, A. O. Chieppe, E. S. M. Araujo, M. C. L. Mendonça, C. C. Dos Santos, C. D. Dos Santos, A. M. Mares-Guia, R. M. R.
Nogueira, P. C. Sequeira, R. G. Abreu, M. H. O. Garcia, A. L. Abreu, O. Okumoto, E. G. Kroon, C. F. C. de Albuquerque, K. Lewandowski, S. T. Pullan, M. Carroll, T. de Oliveira, E. C. Sabino, R. P. Souza, M. A. Suchard, P. Lemey, G. S. Trindade, B. P. Drumond, A. M. B. Filippis, N. J. Loman, S. Cauchemez, L. C. J. Alcantara, O. G. Pybus, Genomic and epidemiological monitoring of yellow fever virus transmission potential. Science 361, 894-899 (2018). doi:10.1126/science.aat7115 Medline

39. J. Quick, N. J. Loman, S. Duraffour, J. T. Simpson, E. Severi, L. Cowley, J. A. Bore, R. Koundouno, G. Dudas, A. Mikhail, N. Ouédraogo, B. Afrough, A. Bah, J. H. Baum, B. Becker-Ziaja, J. P. Boettcher, M. Cabeza-Cabrerizo, A. Camino-Sanchez, L. L. Carter, J. Doerrbecker, T. Enkirch, I. G. G. Dorival, N. Hetzelt, J. Hinzmann, T. Holm, L. E. Kafetzopoulou, M. Koropogui, A. Kosgey, E. Kuisma, C. H. Logue, A. Mazzarelli, S. Meisel, M. Mertens, J. Michel, D. Ngabo, K. Nitzsche, E. Pallash, L. V. Patrono, J. Portmann, J. G. Repits, N. Y. Rickett, A. Sachse, K. Singethan, I. Vitoriano, R. L. Yemanaberhan, E. G. Zekeng, R. Trina, A. Bello, A. A. Sall, O. Faye, O. Faye, N. Magassouba, C. V. Williams, V. Amburgey, L. Winona, E. Davis, J. Gerlach, F. Washington, V. Monteil, M. Jourdain, M. Bererd, A. Camara, H. Somlare, A. Camara, M. Gerard, G. Bado, B. Baillet, D. Delaune, K. Y. Nebie, A. Diarra, Y. Savane, R. B. Pallawo, G. J. Gutierrez, N. Milhano, I. Roger, C. J. Williams, F. Yattara, K. Lewandowski, J. Taylor, P. Rachwal, D. Turner, G. Pollakis, J. A. Hiscox, D. A. Matthews, M. K. O'Shea, A. M. Johnston, D. Wilson, E. Hutley, E. Smit, A. Di Caro, R. Woelfel, K. Stoecker, E. Fleischmann, M. Gabriel, S. A. Weller, L. Koivogui, B. Diallo, S. Keita, A. Rambaut, P. Formenty, S. Gunther, M. W. Carroll, Real-time, portable genome sequencing for Ebola surveillance. Nature 530, 228232 (2016). doi:10.1038/nature16996 Medline

40. R. S. Sikkema, S. D. Pas, D. F. Nieuwenhuijse, Á. O'Toole, J. Verweij, A. van der Linden, I. Chestakova, C. Schapendonk, M. Pronk, P. Lexmond, T. Bestebroer, R. J. Overmars, S. van Nieuwkoop, W. van den Bijllaardt, R. G. Bentvelsen, M. M. L. van Rijen, A. G. M. Buiting, A. J. G. van Oudheusden, B. M. Diederen, A. M. C. Bergmans, A. van der Eijk, R. Molenkamp, A. Rambaut, A. Timen, J. A. J. W. Kluytmans, B. B. Oude Munnink, M. F. Q. Kluytmans van den Bergh, M. P. G. Koopmans, COVID-19 in health-care workers in three hospitals in the south of the Netherlands: A cross-sectional study. Lancet Infect. Dis. 20, 1273-1280 (2020). doi:10.1016/S1473-3099(20)30527-2 Medline

41. P. Simmonds, Rampant C $\rightarrow$ U Hypermutation in the Genomes of SARS-CoV-2 and Other Coronaviruses: Causes and Consequences for Their Short- and Long-Term Evolutionary Trajectories. mSphere 5, e00408-20 (2020). doi:10.1128/mSphere.00408-20 Medline

42. D. S. Candido, I. M. Claro, J. G. de Jesus, W. M. Souza, F. R. R. Moreira, S. Dellicour, T. A. Mellan, L. du Plessis, R. H. M. Pereira, F. C. S. Sales, E. R. Manuli, J. Thézé, L. Almeida, M. T. Menezes, C. M. Voloch, M. J. Fumagalli, T. M. Coletti, C. A. M. da Silva, M. S. Ramundo, M. R. Amorim, H. H. Hoeltgebaum, S. Mishra, M. S. Gill, L. M. Carvalho, L. F. Buss, C. A. Prete Jr., J. Ashworth, H. I. Nakaya, P. S. Peixoto, O. J. Brady, S. M. Nicholls, A. Tanuri, Á. D. Rossi, C. K. V. Braga, A. L. Gerber, A. P. de C Guimarães, N. Gaburo Jr., C. S. Alencar, A. C. S. Ferreira, C. X. Lima, J. E. Levi, C. Granato, G. M. Ferreira, R. S. Francisco Jr., F. Granja, M. T. Garcia, M. L. Moretti, M. W. Perroud Jr., T. M. P. P. Castiñeiras, C. S. Lazari, S. C. Hill, A. A. de Souza Santos, C. L. Simeoni, J. Forato, A. C. Sposito, A. Z. Schreiber, M. N. N. Santos, C. Z. de Sá, R. P. Souza, L. C. Resende-Moreira, M. M. Teixeira, J. Hubner, P. A. F. Leme, R. G. Moreira, M. L. Nogueira, N. M. Ferguson, S. F. Costa, J. L. ProencaModena, A. T. R. Vasconcelos, S. Bhatt, P. Lemey, C. H. Wu, A. Rambaut, N. J. Loman, R. S. Aguiar, O. G. Pybus, E. C. Sabino, N. R. Faria; Brazil-UK Centre for Arbovirus Discovery, Diagnosis, Genomics and Epidemiology (CADDE) Genomic Network, Evolution and epidemic spread of SARS-CoV-2 in Brazil. Science 369, 1255-1260 (2020). doi:10.1126/science.abd2161 Medline

43. T. Ganyani, C. Kremer, D. Chen, A. Torneri, C. Faes, J. Wallinga, N. Hens, Estimating the generation interval for coronavirus disease (COVID-19) based on symptom onset data, March 2020. Euro Surveill. 25, 2000257 (2020). doi:10.2807/15607917.ES.2020.25.17.2000257 Medline

44. E. Cahan, COVID-19 hits U.S. mink farms after ripping through Europe. Science 10.1126/science.abe3870 (2020). doi:10.1126/science.abe3870

45. Promed Post - ProMED-mail, (available at https://promedmail.org/promedpost/?id=7584560).

46. Promed Post - ProMED-mail, (available at https:/promedmail.org/promedpost $/$ ?id $=20200617.7479510$ ). 
47. RIVM, Signaleringsoverleg zoönosen | RIVM, (available at www.rivm.n//surveillance-van-infectieziekten/signaleringinfectieziekten/signaleringsoverleg-zoonosen)

48. RIVM, Outbreak Management Team (OMT) | RIVM, (available at www.rivm.nl/coronavirus-covid-19/omt).

49. A. Kroneman, H. Vennema, K. Deforche, H. v. d. Avoort, S. Peñaranda, M. S. Oberste, J. Vinjé, M. Koopmans, An automated genotyping tool for enteroviruses and noroviruses. J. Clin. Virol. 51, 121-125 (2011). doi:10.1016/i.jcv.2011.03.006 Medline

50. V. M. Corman, O. Landt, M. Kaiser, R. Molenkamp, A. Meijer, D. K. Chu, T. Bleicker, S. Brünink, J. Schneider, M. L. Schmidt, D. G. Mulders, B. L. Haagmans, B. van der Veer, S. van den Brink, L. Wijsman, G. Goderski, J.-L. Romette, J. Ellis, M. Zambon, M. Peiris, H. Goossens, C. Reusken, M. P. Koopmans, C. Drosten, Detection of 2019 novel coronavirus (2019-nCoV) by real-time RT-PCR. Euro Surveill. 25, 2000045 (2020). doi:10.2807/1560-7917.ES.2020,25.3.2000045 Medline

51. C. H. GeurtsvanKessel, N. M. A. Okba, Z. Igloi, S. Bogers, C. W. E. Embregts, B. M. Laksono, L. Leijten, C. Rokx, B. Rijnders, J. Rahamat-Langendoen, J. P. C. van den Akker, J. J. A. van Kampen, A. A. van der Eijk, R. S. van Binnendijk, B. Haagmans, M. Koopmans, An evaluation of COVID-19 serological assays informs future diagnostics and exposure assessment. Nat. Commun. 11, 3436 (2020). doi:10.1038/s41467-020-17317-y Medline

52. R. R. Wick, GitHub - rrwick/Porechop: adapter trimmer for Oxford Nanopore reads, (available at https://github.com/rrwick/porechop).

53. B. B. Oude Munnink, D. F. Nieuwenhuijse, R. S. Sikkema, M. Koopmans, Validating Whole Genome Nanopore Sequencing, using Usutu Virus as an Example. J. Vis. Exp. 10.3791/60906 (2020). doi:10.3791/60906 Medline

54. T. Seemann, F. Klotzl, A. Page, GitHub - tseemann/snp-dists: Pairwise SNP distance matrix from a FASTA sequence alignment, (available at https://github.com/tseemann/snp-dists).

55. R. C. Edgar, MUSCLE: Multiple sequence alignment with high accuracy and high throughput. Nucleic Acids Res. 32, 1792-1797 (2004). doi:10.1093/nar/gkh340 Medline

56. L. T. Nguyen, H. A. Schmidt, A. von Haeseler, B. Q. Minh, IQ-TREE: A fast and effective stochastic algorithm for estimating maximum-likelihood phylogenies. Mol. Biol. Evol. 32, 268-274 (2015). doi:10.1093/molbev/msu300 Medline

57. A. Rambaut, FigTree (2016), (available at http://tree.bio.ed.ac.uk/software/figtree/).

58. Y. Shu, J. McCauley, GISAID: Global initiative on sharing all influenza data - from vision to reality. Euro Surveill. 22, 30494 (2017). doi:10.2807/15607917.ES.2017.22.13.30494 Medline

59. H. Wickham, ggplot2: Elegant Graphics for Data Analysis (Springer-Verlag, New York, 2016).

60. C.-C. B. voor de Statistiek, Wijk- en buurtkaart 2019, (available at www.cbs.nl/nl$\mathrm{n}$ /dossier/nederland-regionaal/geografische-data/wijk-en-buurtkaart-2019).

61. E. J. Pebesma, R. S. Bivand, Classes and Methods for Spatial Data: The sp Package. R News 5, 9-13 (2005); https://CRAN.R-project.org/doc/Rnews/.

62. GitHub - rspatial/raster: $\mathrm{R}$ raster package, (available at https://github.com/rspatial/raster/).

63. cran/rgdal, (available at https://github.com/cran/rgdal).

\section{ACKNOWLEDGMENTS}

We would like to acknowledge Robin van Houdt, Janke Schinkel, Jelle Koopsen and Rens Zonneveld (Amsterdam UMC), Bas Wintermans (ARDZ), Eva Schmid (GGD Goes), Babette Rump (GGD Zeeland), Jacky Filipse and Claudy Oliveira dos Santos (Isala Hospital, Laboratory of Clinical Microbiology and Infectious Diseases), Theo Schuurs (Izore), Roel Nijhuis (Meander Medisch Centrum), Suzan Pas (Microvida), Bertie de Leeuw (RLM Microbiologie) and Ruud Jansen, Jayant Kalpoe and Wil van der Reijden (Streeklab Haarlem) for sample provision and Anne van der Linden, Marjan Boter and Irina Chestakova from the ErasmusMC for technical assistance. Funding: This work has received funding from the European Union's Horizon 2020 research and innovation program under grant agreement No. 874735 (VEO), No. 848096 (SHARP JA) and No. 101003589 (RECoVER), from ZonMW (grant agreement No. 10150062010005), and from the Netherlands Ministry of Agriculture, Nature and Foods. Author contributions: Conceptualization: B.B.O.M, R.S.S, A.S., M.P.G.K; investigation:
B.B.O.M, D.F.N., R.S.S, A.S., M.P.G.K, L.A.M.S, W.H.N.v.d.P, R.J.M, R.J.B, E.M, R.M, A.v.d.S, P.T, A.R, M.B, N.B-V, F.H, R.H.v.d.H, M.C.A.W-B, R.J.B, C.G, A.A.v.d.E, F.C.V, L.A.M.S; supervision: M.P.G.M; writing original draft: B.B.O.M, R.S.S, M.P.G.K; writing review and editing, all authors. Competing interests: Authors declare no competing interests. Data and material availability: All data, code and materials used described in this manuscript are publicly available. All sequences are publicly available in the GISAID database under the accessions: EPI_ISL_461190 - EPI_ISL_461192, EPI_ISL_461200, EPI_ISL_461202, EPI_ISL_461203, EPI_ISL_522987 - EPI_ISL_523034, EPI_ISL_523040, EPI_ISL_523046, EPI_ISL_523068, EPI_ISL_523070, EPI_ISL_523072, EPI_ISL_523073, EPI_ISL_523075, EPI_ISL_523085, EPI_ISL_523089 EPI_ISL_523120, EPI_ISL_523282 - EPI_ISL_523286, EPI_ISL_523301, EPI_ISL_523310 - EPI_ISL_523312, EPI_ISL_523333, EPI_ISL_523493 and EPI_ISL_523494. Ethical approval was not required for this study as anonymous aggregated data were used, and no medical interventions were made on animal or human subjects. This work is licensed under a Creative Commons Attribution 4.0 International (CC BY 4.0) license, which permits unrestricted use, distribution, and reproduction in any medium, provided the original work is properly cited. To view a copy of this license, visit

https://creativecommons.org/licenses/by/4.0/. This license does not apply to figures/photos/artwork or other content included in the article that is credited to a third party; obtain authorization from the rights holder before using such material.

\section{SUPPLEMENTARY MATERIALS}

science.sciencemag.org/cgi/content/full/science.abe5901/DC1

Materials and Methods

Fig. S1

Table S1

References (47-63)

MDAR Reproducibility Checklist

1 September 2020; accepted 5 November 2020

Published online 10 November 2020

10.1126/science.abe5901 


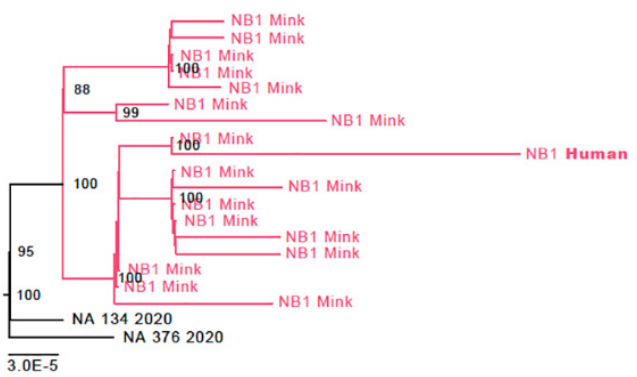

Fig. 1. Phylogenetic analysis of mink farm NB1. A maximum likelihood analysis was performed using all available SARS-CoV-2 Dutch sequences. Sequences from NB1 are depicted in red and the employee on NB1 is depicted in bold. The two sequences in black at the root of the cluster are the closest matching human genome sequences from the national SARS-CoV-2 sequence database. Scale bar units represent numbers of substitutions per site.
Fig. 2. Maximum likelihood analysis of all SARS-CoV-2 Dutch sequences. The sequences derived from minks from different farms are indicated with different colors, human sequences related to the mink farms are shown in blue and samples from similar 4digit postal code are shown in magenta. The sequences derived from different farms are depicted in different colors. Scale bar represents units of substitutions per site.

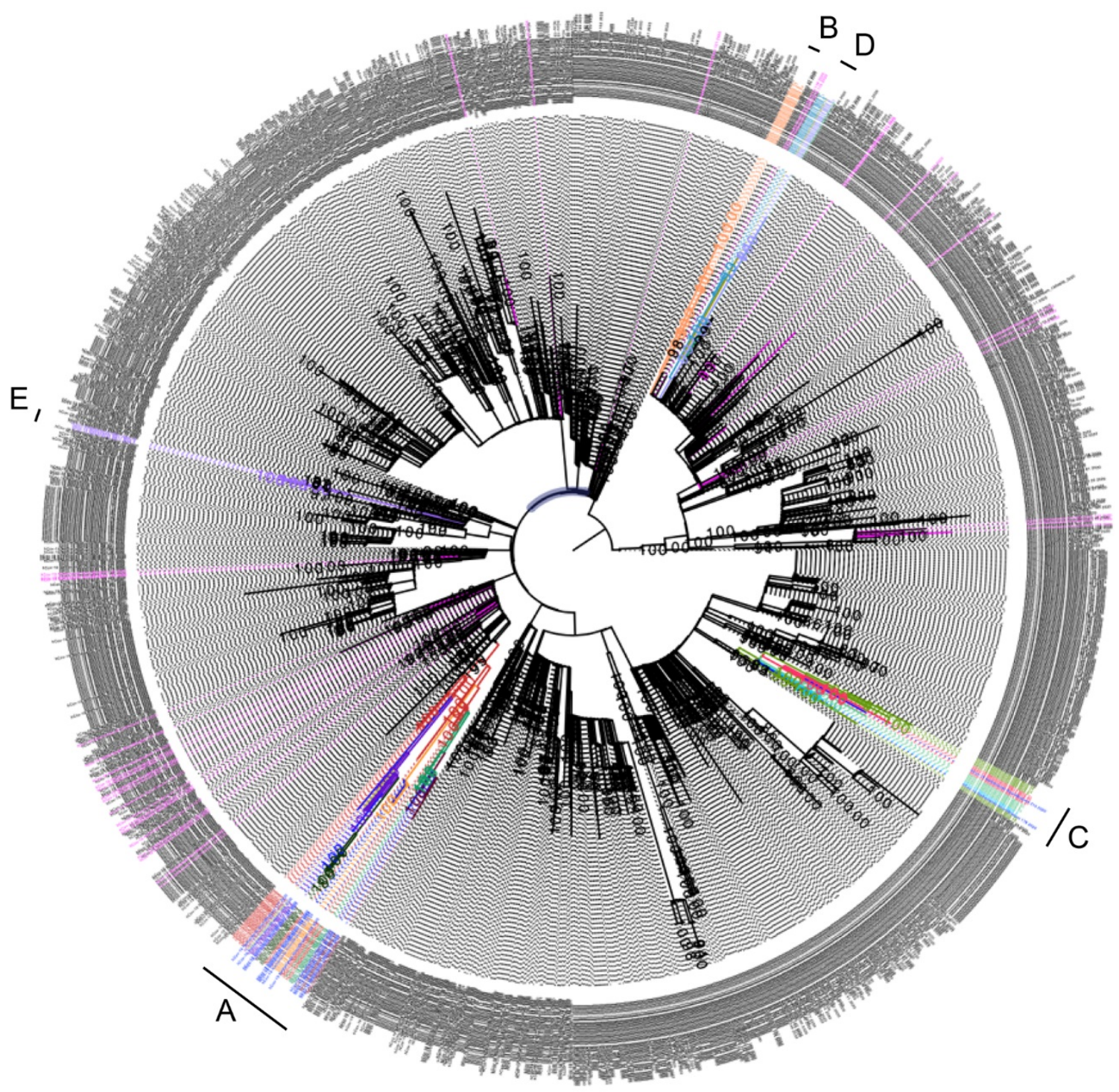

$6.0 \mathrm{E}-5$

First release: 10 November 2020 
$\overline{3.0 \mathrm{E}-5}$
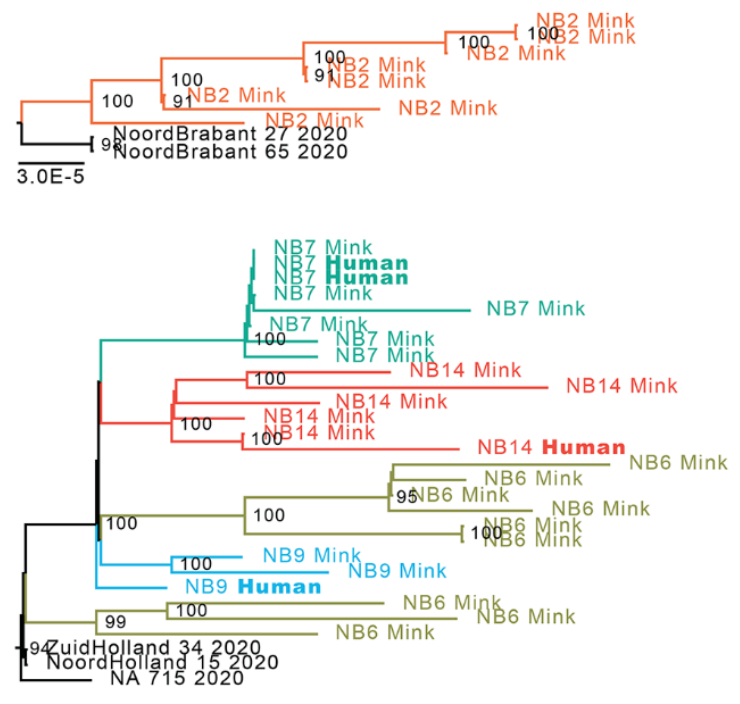

$\overline{3.0 \mathrm{E}-5}$

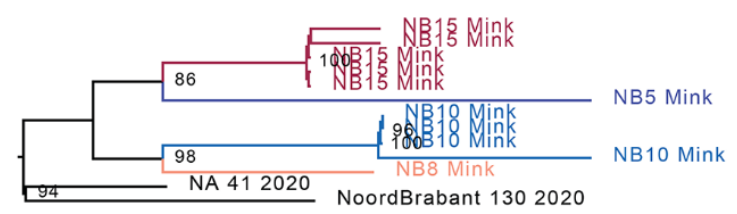

$\overline{3.0 \mathrm{E}-5}$

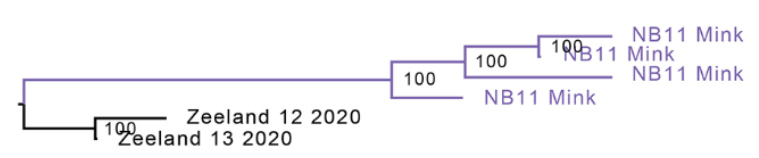

$\overline{3.0 \mathrm{E}-5}$
Fig. 3. Phylogenetic analysis of 88 mink and 18 mink-related human SARS-CoV2 sequences detected in the 5 mink farm clusters. The sequences derived from different farms are depicted in different colors. Scale bar represents units of substitutions per site. 


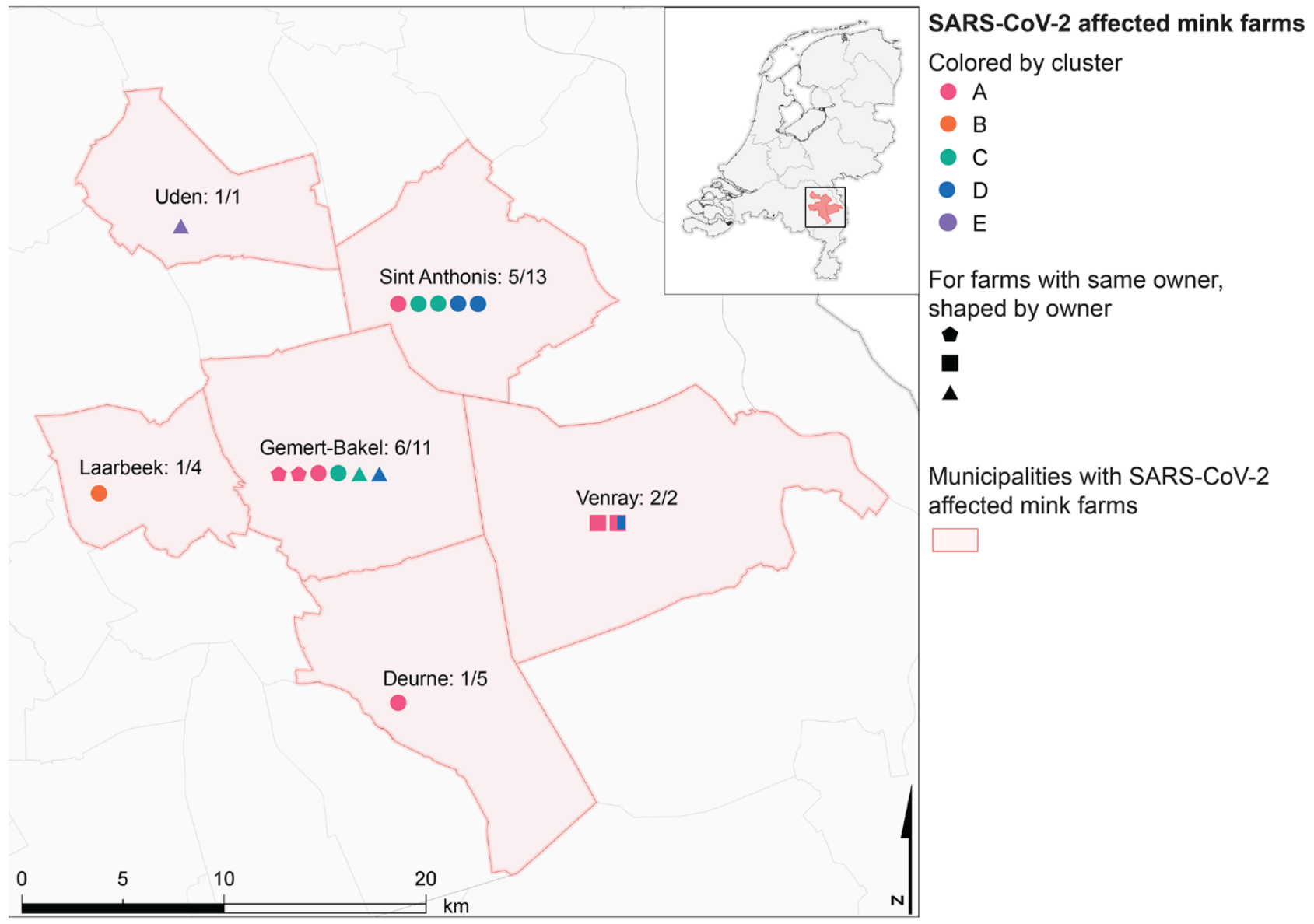

Fig. 4. Geographical overview of SARS-CoV-2 positive mink farms per municipality affected. The proportion of SARS-CoV-2 positive mink farms over the total number of mink farms (CBS, 2019) is indicated. Symbols for positive farms are colored by cluster and shapes indicate farms with a single owner. 
Table 1. Overview of human sampling on SARS-CoV-2 positive mink farms.

\begin{tabular}{|c|c|c|c|c|c|}
\hline Farm & $\begin{array}{l}\text { First } \\
\text { diagnosis in } \\
\text { animals }\end{array}$ & $\begin{array}{l}\text { Date(s) of sampling } \\
\text { employees and family } \\
\text { members }\end{array}$ & $\begin{array}{l}\text { PCR positive } \\
(\%)\end{array}$ & $\begin{array}{l}\text { Serology } \\
\text { positive (\%) }\end{array}$ & $\begin{array}{l}\text { Employees and family } \\
\text { members tested } \\
\text { positive (PCR and/or } \\
\text { serology) }\end{array}$ \\
\hline NB1 & $23-04-2020$ & $\begin{array}{l}28-04-2020-11-05- \\
2020\end{array}$ & $5 / 6(83 \%)$ & $5 / 5(100 \%)$ & $6 / 6(100 \%)$ \\
\hline NB2 & $25-04-2020$ & $\begin{array}{l}31-03-2020-30-04- \\
2020\end{array}$ & $1 / 2(50 \%)$ & $7 / 8(88 \%)$ & $7 / 8(88 \%)$ \\
\hline NB3 & $07-05-2020$ & $\begin{array}{l}11-05-2020-26-05- \\
2020\end{array}$ & $5 / 7(71 \%)$ & $0 / 6(0 \%)^{*}$ & $5 / 7(71 \%)$ \\
\hline NB4 & $07-05-2020$ & $08-05-2020$ & $1 / 3(33 \%)$ & $2 / 2(100 \%)$ & $2 / 3(66 \%)$ \\
\hline NB5 & $31-05-2020$ & $01-06-2020$ & $2 / 7(29 \%)$ & $3 / 6(50 \%)$ & $3 / 7(43 \%)$ \\
\hline NB6 & $31-05-2020$ & $01-06-2020$ & $1 / 6(17 \%)$ & $4 / 6(66 \%)$ & $4 / 6(66 \%)$ \\
\hline NB7 & $31-05-2020$ & $\begin{array}{l}10-06-2020 \text { - 01-07- } \\
2020\end{array}$ & $8 / 10(80 \%)$ & $N A^{* *}$ & $8 / 10(80 \%)$ \\
\hline NB8 & $02-06-2020$ & $03-06-2020$ & $5 / 10(50 \%)$ & $5 / 9(56 \%)$ & $8 / 10(80 \%)$ \\
\hline NB9 & $04-06-2020$ & 07-06-2020 & $1 / 7(14 \%)$ & $1 / 7(14 \%)$ & $2 / 7(29 \%)$ \\
\hline NB10 & 08-06-2020 & $11-06-2020$ & $1 / 8(13 \%)$ & $3 / 8(38 \%)$ & $4 / 8(50 \%)$ \\
\hline NB11 & $08-06-2020$ & $11-06-2020$ & $1 / 3(33 \%)$ & $0 / 2(0 \%)$ & $1 / 3(33 \%)$ \\
\hline NB12 & $09-06-2020$ & $11-06-2020$ & $6 / 9(66 \%)$ & $2 / 8(25 \%)$ & 7/9 (78\%) \\
\hline NB13 & $14-06-2020$ & $\begin{array}{l}11-06-2020-18-06- \\
2020\end{array}$ & $3 / 3(100 \%)$ & $0 / 2(0 \%)$ & $3 / 3(100 \%)$ \\
\hline NB14 & $14-06-2020$ & $14-06-2020$ & $1 / 3(33 \%)$ & $5 / 6(83 \%)$ & $5 / 6(83 \%)$ \\
\hline NB15 & $21-06-2020$ & $\begin{array}{l}10-06-2020-30-06- \\
2020\end{array}$ & $2 / 2(100 \%)$ & $N A^{* *}$ & $2 / 2(100 \%)$ \\
\hline NB16 & $21-06-2020$ & $23-06-2020$ & $0 / 2(0 \%)$ & $N A^{* *}$ & $0 / 2(0 \%)$ \\
\hline Total & & & $43 / 88(49 \%)$ & $37 / 75$ (49\%) & $66 / 97(68 \%)$ \\
\hline
\end{tabular}

*Serology was done approximately one week before the positive PCR test.

**No serology was performed. 
Table 2. Overview of the clusters detected on the different farms.

\begin{tabular}{|c|c|c|c|c|c|c|c|c|c|}
\hline Farm & $\begin{array}{l}\text { Date of } \\
\text { diagnosis }\end{array}$ & $\begin{array}{l}\text { Sequence } \\
\text { cluster }\end{array}$ & $\begin{array}{l}\text { Same } \\
\text { owner }\end{array}$ & $\begin{array}{l}\text { Feed } \\
\text { supplier }\end{array}$ & $\operatorname{Vet}^{* *}$ & $\begin{array}{l}\text { Number of } \\
\text { sequences } \\
\text { (+human) }\end{array}$ & $\begin{array}{l}\text { SNPs } \\
\text { differences } \\
\text { (average) }\end{array}$ & $\begin{array}{l}\text { Mink } \\
\text { population } \\
\text { size }\end{array}$ & Detection ${ }^{* * *}$ \\
\hline NB1 & $24-04-20$ & $A$ & $\begin{array}{l}\text { NB1, } \\
\text { NB4 }\end{array}$ & 1 & $\mathrm{I}$ & $17(+1)$ & $0-9(3.9)$ & 75,711 & Notification \\
\hline NB2 & $25-04-20$ & B & & 1 & II & 8 & $0-8(3.6)$ & 50,473 & Notification \\
\hline NB3 & $07-05-20$ & $A$ & & 2 & III & $5(+5)$ & $0-2(0.6)$ & 12,400 & Notification \\
\hline NB4 & $07-05-20$ & $A$ & $\begin{array}{l}\text { NB1, } \\
\text { NB4 }\end{array}$ & 1 & I & 1 & NA & 67,945 & $\begin{array}{l}\text { Contact } \\
\text { tracing NB1 }\end{array}$ \\
\hline NB5 & $31-05-20$ & $D$ & & 1 & IV & 1 & NA & 38,936 & $\begin{array}{l}\text { EWS-Ser+PM- } \\
\text { 1st }\end{array}$ \\
\hline NB6 & $31-05-20$ & C & & 3 & V & 9 & $0-12(6.8)$ & 54,515 & $\begin{array}{l}\text { EWS-Ser+PM- } \\
\text { 1st }\end{array}$ \\
\hline NB7 & $31-05-20$ & C & $\begin{array}{l}\text { NB7, } \\
\text { NB11, } \\
\text { NB15 }\end{array}$ & 3 & II & $6(+2)$ & $0-4(1.4)$ & 79,355 & EWS-PM-1st \\
\hline NB8 & $02-06-20$ & $A / D$ & $\begin{array}{l}\text { NB8, } \\
\text { NB12* }\end{array}$ & 3 & V & $6(+5)$ & $0-6(2.6)$ & 39,144 & $\begin{array}{l}\text { EWS-Ser+PM- } \\
\text { lst }\end{array}$ \\
\hline NB9 & $04-06-20$ & C & & 2 & V & $2(+1)$ & $0-3(1.5)$ & 32,557 & $\begin{array}{l}\text { EWS-Ser+PM- } \\
\text { 2nd }\end{array}$ \\
\hline NB10 & $08-06-20$ & $D$ & & 3 & II & 4 & $0-3(1.1)$ & 26,824 & $\begin{array}{l}\text { EWS-Ser+PM- } \\
\text { 2nd }\end{array}$ \\
\hline NB11 & $08-06-20$ & $\mathrm{E}$ & $\begin{array}{l}\text { NB7, } \\
\text { NB11, } \\
\text { NB15 }\end{array}$ & 3 & II & 4 & $0-4(2.2)$ & 38,745 & EWS-PM-2nd \\
\hline NB12 & $09-06-20$ & $A$ & $\begin{array}{l}\text { NB8, } \\
\text { NB12* }\end{array}$ & 3 & ॥ & 5 & $0-3(1.2)$ & 55,352 & Notification \\
\hline NB13 & $14-06-20$ & A & & 3 & V & $5(+3)$ & $0-5(3.2)$ & 20,366 & EWS-PM-5th \\
\hline NB14 & $14-06-20$ & C & & 3 & ॥ & $5(+1)$ & $0-7(3.7)$ & 28,375 & EWS-PM-5th \\
\hline NB15 & $21-06-20$ & $\mathrm{D}$ & $\begin{array}{l}\text { NB7, } \\
\text { NB11, } \\
\text { NB15 }\end{array}$ & 3 & $\|$ & 5 & $0-2(0.6)$ & 35,928 & EWS-PM-6th \\
\hline NB16 & $21-06-20$ & $A$ & & 3 & ॥ & 5 & $0-4(1.6)$ & 66,920 & EWS-PM-6th \\
\hline
\end{tabular}

*There was exchange of personnel in these two locations.

**Veterinarian II and $\mathrm{V}$ were both from the same veterinary practice.

***Notification: based on reporting of clinical signs which was obligated from 26 April onwards; EWS-Ser-Detection based on a one-off nationwide compulsory serological screening of all mink farms at the end of May/early June by GD Animal Health; EWS-PM-Detection based on the early warning monitoring system for which carcasses of animals that died of natural causes were submitted weekly for PCR testing by GD Animal Health from the end of May onwards in a weekly cycle (EWS-PM 1st to 6th post mortem screening). 